\title{
Advances in Understanding Visual Cortex Plasticity
}

\author{
Portia A. McCoy, \\ Department of Cell and Molecular Physiology, Neuroscience Center, Curriculum in Neurobiology, \\ and Neurodevelopmental Disorders Research Center, University of North Carolina, Campus Box \\ 7545, 115 Mason Farm Rd, Chapel Hill, NC 27599-7545 e-mail: portia@med.unc.edu \\ Hsien-Sung Huang, and \\ Department of Cell and Molecular Physiology, Neuroscience Center, Curriculum in Neurobiology, \\ and Neurodevelopmental Disorders Research Center, University of North Carolina, Campus Box \\ 7545, 115 Mason Farm Rd, Chapel Hill, NC 27599-7545, e-mail: huang.hsiensung@gmail.com
}

\section{Benjamin D. Philpot \\ Department of Cell and Molecular Physiology, Neuroscience Center, Curriculum in Neurobiology, and Neurodevelopmental Disorders Research Center, University of North Carolina, Campus Box 7545, 115 Mason Farm Rd, Chapel Hill, NC 27599-7545, e-mail: bphilpot@med.unc.edu}

\section{Summary of recent advances}

\begin{abstract}
Visual cortical plasticity can be either rapid, occurring in response to abrupt changes in neural activity, or slow, occurring over days as a homeostatic process for adapting neuronal responsiveness. Recent advances have shown that the magnitude and polarity of rapid synaptic modifications are regulated by neuromodulators, while homeostatic modifications can occur through regulation of cytokine actions or NMDA receptor subunit composition. Synaptic and homeostatic plasticity together produce the normal physiological response to monocular impairments. In vivo studies have now overturned the dogma that robust plasticity is limited to an early critical period. Indeed, rapid physiological plasticity in the adult can be enabled by prior, experience-driven anatomical rearrangements or through pharmacological manipulations of the epigenome.
\end{abstract}

\section{Introduction}

Coordinated, experience-driven changes in synaptic efficacy are required for the proper development of brain networks. This plasticity has been well-studied in the visual cortex, as a brief period of monocular deprivation produces amblyopia (loss of vision) as a consequence of reduced synaptic inputs to the cortex. The weakening of the deprived-eye response is often followed by a delayed enhancement of the open-eye response [1]. These modifications occur through input-specific strengthening and weakening of synapses, which have been studied in the forms of long-term depression (LTD) and long-term potentiation (LTP). Importantly, the molecular and physiological signatures of in vitro plasticity mirror those that occur naturally [2]. LTD and LTP can be rapidly induced by varying the stimulation frequency of presynaptic

\footnotetext{
(C) 2009 Elsevier Ltd. All rights reserved.

Correspondence to: Benjamin D. Philpot.

Publisher's Disclaimer: This is a PDF file of an unedited manuscript that has been accepted for publication. As a service to our customers we are providing this early version of the manuscript. The manuscript will undergo copyediting, typesetting, and review of the resulting proof before it is published in its final citable form. Please note that during the production process errors may be discovered which could affect the content, and all legal disclaimers that apply to the journal pertain.
}

Conflicts of Interest

None. 
inputs (frequency-dependent plasticity) or the relative timing between the presynaptic and postsynaptic firing of action potentials (spike timing-dependent plasticity; STDP).

LTD- and LTP- like processes may not be sufficient to fully describe naturally occurring plasticity observed in vivo. Homeostatic changes in synaptic efficacy may also be required to fully account for the development of synapses and their modification by experience. In this paradigm, prolonged changes in neural activity produce a cell-wide compensation, either by globally altering synaptic strength [3••] or shifting the threshold for the subsequent induction of LTD/LTP [4].

Researchers have passionately sought the mechanisms underlying frequency-dependent, spike timing-dependent, and homeostatic forms of plasticity. Insights into these mechanisms are expected to guide clinical therapies to prevent or reverse visual derangements such as amblyopia, or may be more generalized to treating disorders of the synapse. In this review we highlight recent advances in our understanding of the signaling mechanisms implicated in visual cortical plasticity. We will briefly discuss (i) the importance of neuromodulation, (ii) the homeostatic contributions to experience-dependent modeling of cortical microcircuits, (iii) plasticity in the mature visual cortex, and (iv) the emerging appreciation of epigenetic influences.

\section{Neuromodulation of synaptic plasticity}

The neuromodulators acetylcholine (ACh) and norepinephrine (NE) enhance visual cortex plasticity observed in vivo following monocular deprivation [5,6]. Several in vitro studies have shown that ACh and NE can cause the induction or enhancement of synaptic plasticity. However, the results of these studies have often appeared contradictory. Such discrepancies have likely arisen because multiple receptor subtypes and their signaling cascades can be engaged by these neuromodulators. Recent studies have taken advantage of more selective pharmacologic and genetic manipulations to address this issue. These studies demonstrate that either muscarinic ACh or $\alpha_{1}$-adrenergic receptors coupled to phospholipase $\mathrm{C}$ signaling pathways induce or enhance LTD ([7-10••]; but see [11]). In contrast, activation of muscarinic ACh or $\beta$-adrenergic receptors coupled to adenylyl cyclase can enhance or induce LTP [9, 12]. Thus, the same neuromodulator can both strengthen and weaken synaptic connections, and the valence of the plasticity is dictated by the precise receptor subtype and signaling pathway enlisted (Figure 1).

The ability of neuromodulators to alter the valence of synaptic plasticity is particularly salient in STDP. Two critical components for determining the magnitude and direction of changes in synaptic strength are the relative timing (within $\sim 50 \mathrm{~ms}$ window) and the temporal order of the pre- and post-synaptic action potentials. However, information encoded by the temporal order of action potential firing is dependent upon which signaling pathways are activated. Kirkwood and colleagues [10••] elegantly showed that neuromodulators can dictate the outcome of STDP through the signaling pathways they engage. When adenylyl cyclase signaling pathways are stimulated through $\beta$-adrenergic receptors, LTP is induced regardless of the temporal order in which the presynaptic and postsynaptic action potentials occurred. In contrast, activation of phospholipase C through M1 muscarinic ACh or $\alpha_{1}$-adrenergic receptors causes the induction of LTD and prevents the induction of LTP across timing intervals. Thus, to enable the temporal relevance of spike timing to induce both LTD and LTP, both phospholipase $\mathrm{C}$ and adenylyl cyclase neuromodulatory pathways are necessary. The unique downstream targets of these pathways are currently unknown, although some evidence suggests that the pathways differentially phosphorylate glutamate receptor subunits and thereby alter their function $[10 \bullet \cdot$. These data indicate that, equally important to the exact timing 
of presynaptic and postsynaptic events, interactions amongst neuromodulatory inputs are necessary to produce the full range of timing-dependent plasticities.

These studies show a clear importance of neuromodulators, and their different signaling pathways, to the induction of synaptic plasticity. Future studies may be able to take advantage of neuromodulatory systems when attempting to reinstate plasticity that is diminished through age or disease. In support of this idea, a classic study has demonstrated that infusions of NE into the adult cortex can restore ocular dominance plasticity [6].

\section{Homeostatic synaptic plasticity}

The development and modification of neuronal properties in visual cortex cannot be described by a model that simply employs the rapid, activity-dependent induction of LTD and LTP. For example, it is difficult to account for the delayed increase in the open-eye response following monocular deprivation with a strict LTD/LTP model, as this increase occurs days after the more immediate loss of responsiveness to the deprived eye [1]. This delayed response to monocular deprivation is thought to be necessary for maintaining neuronal responsiveness within an optimal range. Such plasticity can be explained by two proposed homeostatic mechanisms: synaptic scaling and a sliding threshold of synaptic plasticity (a form of metaplasticity). In synaptic scaling, a decrease (or increase) in neuronal firing is compensated for by a global scaling up (or down) of excitatory synaptic strength [3・•]. In metaplasticity, diminished neuronal activity produces a global reduction in the threshold for synaptic potentiation, making it more likely that synapses will be potentiated, while heightened neuronal activity raises this threshold [13].

There is now clear evidence that synaptic scaling can occur both in vitro and in vivo. In vitro, reductions in neuronal firing by tetrodotoxin (TTX) treatment produce a robust and reliable scaling up of synaptic strengths [3••]. In vivo, monocular deprivation by intraocular injection of TTX or binocular deprivation with dark-rearing can produce synaptic scaling in layer 4 and layers $2 / 3[14,15]$. An exciting observation is that there is a clear developmental shift in the expression of synaptic scaling. Synaptic scaling of excitatory synapses is first observed in layer 4 and then in layers $2 / 3$. Unlike layer 4 , synaptic scaling appears to be maintained throughout life in layers $2 / 3$ [15], mirroring the maintenance of LTD/LTP in these superficial layers [16]. Interestingly, the qualities of synaptic scaling shift with age so that multiplicative scaling is no longer observed in more mature animals [15].

Does synaptic scaling contribute to the observed physiological response to monocular deprivation? The recent finding that the cytokine TNF $\alpha$ is required for synaptic scaling has now allowed this question to be addressed [17•]. The genetic or molecular knockdown of $\mathrm{TNF} \alpha$, and hence synaptic scaling, did not prevent the loss of the deprived eye response in the visual cortex following monocular deprivation [17•]. However, the delayed increase in the open eye response was prevented, suggesting a critical role for synaptic scaling. These data indicate that both rapid Hebbian plasticity and slower homeostatic processes combine to produce the full physiological response to changes in sensory experience.

Metaplasticity, another prominent model of homeostatic plasticity, incorporates an experiencedependent sliding threshold for LTD/LTP induction. Together with LTD and LTP, the sliding threshold for synaptic modifications was integrated into a theoretical model that could account for the experimentally observed consequences of sensory deprivation [4]. Unlike the synaptic scaling model, a sliding plasticity threshold has the additional advantage of being able to account for the acquisition of stimulus-selective properties (e.g. orientation selectivity). Evidence for a sliding threshold comes from the observation that dark-rearing lowers the LTP induction threshold recorded ex vivo, while visual experience increases this threshold [18]. The lowering of the LTP threshold is paralleled by a reduction in the ratio of NMDA receptors 
containing the NR2A subunit compared to the NR2B subunit [19]. Consistent with the idea that the NR2A/NR2B ratio adjusts the threshold for synaptic modifications, experiencedependent metaplasticity is absent in mice that lack NR2A [20].

Two lines of evidence suggest that metaplasticity can account for the acquisition of stimulusselective neuronal properties and experience-dependent modifications. First, as predicted from theoretical models, mice lacking metaplasticity due to the genetic deletion of NR2A exhibit broad orientation selectivity [21]. This suggests that homeostatic adjustment of the plasticity threshold facilitates the acquisition of stimulus selectivity in neurons. Second, genetic deletion of NR2A impairs the biphasic response to monocular deprivation. While wildtype mice exhibit a rapid depression of the deprived eye response and a delayed ( $\sim 5$ days) potentiation of the open eye response after monocular deprivation, NR2A knockout mice instead exhibit only a rapid ( $\sim 1$ day) open eye potentiation [22]. Coupled to the observation that a reduction in NR2A/ NR2B normally precedes the delayed potentiation of the open eye response in wildtype mice, these data indicate that a change in NMDA receptor subunit composition is a naturally occurring event for reducing the threshold for synaptic potentiation.

Whether synaptic scaling or a sliding threshold of plasticity is physiologically employed has been a contentious issue, but the distinction between the two may be an artifact of the complexity and heterogeneity of the neocortex. By analogy, the mechanisms of cortical LTD and LTP were originally thought to be homologous to those occurring in the CA1 region of the hippocampus, however recent studies have revealed the incredible diversity of plasticity mechanisms across development and the various cortical microcircuits [14,16,23,24]. Homeostatic mechanisms may exhibit a similar heterogeneity. In support of this idea, the homeostatic response to monocular deprivation can vary tremendously with the manner of deprivation [25]. Specifically, monocular TTX treatment leads to a scaling up of excitatory connections and a scaling down of inhibitory connections onto layer $2 / 3$ neurons. In contrast, monocular lid suture fails to induce the predicted synaptic scaling, but instead maintains responsiveness of layer $2 / 3$ neurons by changing their intrinsic membrane properties.

We propose that synaptic scaling and metaplasticity are non-mutually exclusive homeostatic mechanisms that are both required for the full repertoire of physiological modifications by sensory experience. Future studies using mutant mice that lack synaptic scaling or metaplasticity may be used to parse the relative contributions of each process, and to test the possibility that these processes may even engage overlapping mechanisms.

\section{Adult plasticity}

The classic work of Hubel and Wiesel instilled the idea that visual cortex plasticity was limited to a critical period of early life [26]. However, elegant work in mice has revealed a remarkable capacity for the adult visual cortex to reorganize following monocular deprivation $[27,28 \bullet \bullet]$. Although the net effect of monocular deprivation in juveniles and adults is to reduce the response of the deprived eye relative to the open eye, the adult plasticity is qualitatively unique. Specifically, adult mice fail to undergo the rapid reduction in the deprived eye response that is observed in juvenile mice, but instead only exhibit the delayed potentiation of the open eye response $[1,28 \bullet \bullet]$.

A major goal in the field has been to reinstate juvenile-like plasticity in the adult visual cortex using pharmacologic and genetic interventions, with the expectation that this will guide therapies for amblyopia. Successful enhancement of adult plasticity has been achieved by altering (i) the excitation to inhibition balance [29,30], (ii) extracellular matrices [31], (iii) neuromodulation [6,30], (iv) inhibitory influences from myelin [32], and (v) growth factor 
functions [33]. In each case, the recovery of plasticity most likely requires complex changes to the local cellular milieu.

Despite the discovery of multiple manipulations that can successfully enhance adult plasticity, none of these have been translated into therapies for amblyopia. An exciting new development is the possibility that behavioral manipulations can be used to enhance adult visual cortex plasticity, as these non-invasive approaches may be more rapidly translated to clinical therapies. Environmental enrichment has been used to facilitate the recovery from amblyopia in adult rodents, through a reduction in GABA-mediated inhibition [34]. Late-onset visual deprivation can also facilitate the recovery from amblyopia [35•], likely through reductions in GABAergic inhibition and the NR2A/NR2B ratio [36]. Additionally, prior monocular deprivation can enable a subsequent rapid ocular dominance shift in adults, akin to that observed during the critical period [27]. Collectively these observations provide compelling evidence that behavioral manipulations can powerfully alter the induction of plasticity in the adult cortex.

Recent observations demonstrate that the re-expression of rapid experience-dependent plasticity in the adult cortex is preceded by profound anatomical changes [37••]. An initial monocular deprivation in the adult cortex, which produces an ocular dominance shift that emerges slowly over $\sim 8$ days, is accompanied by a dramatic and persistent increase in the density of dendritic spines in layer 5 neurons in binocular cortex [37••]. A subsequent monocular deprivation fails to further increase spine density, but now the ocular dominance shift occurs much more rapidly (within $\sim 3$ days), similar to that observed during the critical period. This suggests that anatomical restructuring provides a substrate upon which subsequent physiological modifications may rapidly occur.

While adult plasticity is clearly observed in rodents, several outstanding issues remain. First, is adult visual cortex plasticity limited to rodents, or can robust plasticity be introduced in higher primates, as suggested by a recent human study showing that amblyopic deficits can be transiently ameliorated [38]? Second, does the reintroduction of adult plasticity occur through common signaling mechanisms, or are there multiple pathways for achieving the same end result? Third, is there a causal relationship between the anatomical changes observed in layer 5 and the recovery of rapid ocular dominance plasticity, and if so, do other cell types engage this same mechanism?

\section{Epigenetic mechanisms for visual cortical synaptic plasticity}

During the critical period, even a relatively brief monocular deprivation can lead to a lasting change in ocular dominance. The neural mechanisms for such enduring modifications are still unclear, although the plasticity is undoubtedly activated and maintained through the differential expression of so-called "plasticity genes" that have particularly salient expression during the critical period [39,40]. It seems likely that experience-driven changes in transcription of these plasticity genes act to gate visual cortex plasticity.

Gene transcription can be regulated through chromatin remodeling such as DNA methylation and histone modifications. Chromatin structure likely serves as a platform for relaying and integrating information from numerous experience-driven signaling pathways. In support of this idea, chromatin remodeling complexes are thought to regulate synaptic strength and memory storage via orchestrated alterations in DNA methylation and histone acetylation [41, 42].

Can changes in visual experience (e.g. light) modify the properties of synaptic plasticity by triggering downstream changes to chromatin structure? The answer appears to be an emphatic "yes." For instance, light stimulates phosphorylation and acetylation of histone $\mathrm{H} 3$ in the 
suprachiasmatic nucleus $[43,44]$. In the visual cortex, light induces phosphorylation and acetylation of histone $\mathrm{H} 3$ during the critical period [45•]. Such long-lasting epigenetic changes could alter the activity-dependent strengthening or weakening of synapses, or even trigger homeostatic plasticity, by regulating gene transcription.

Consistent with the idea that epigenetic marks can influence synaptic plasticity, pharmacologically enhancing histone acetylation with the histone deacetylase inhibitor (HDACi) trichostatin restores juvenile-like ocular dominance plasticity in the adult visual cortex [45•]. These findings demonstrate that epigenetic modifications are likely a naturally occurring mechanism for gating critical period plasticity. While the recovery of adult cortical plasticity using a broad spectrum HDACi is promising, such global manipulations are likely to have unintended and undesirable side effects. It is clear, however, that the ability to selectively manipulate epigenetic marks hold great promise for recovering adult plasticity.

Given the broad targeting of the HDACi used for recovering visual plasticity, it is difficult to pinpoint which epigenetic events are critical and which genes are undergoing altered transcription. However, there are some indications that epigenetic influences might alter the transcription of genes signaled through an ERK/MSK/CREB signaling pathway (Figure 2). Synaptic plasticity is associated with signaling pathways, including mitogen-activated protein kinase (MAPK) cascades. The MAPK cascade activated by extracellular signal-regulated kinase (ERK) and its downstream neural targets are necessary for experience-dependent plasticity in the visual cortex (Figure 2) [46]. Visual stimulation during cortical maturation induces site-specific phosphorylation of MSK and CREB [45•]. While visual stimulation during the critical period can also induce posttranslational modifications in histones $\mathrm{H} 3$ and $\mathrm{H} 4$ within the visual cortex, stimulation after the critical period fails to do so. However, the observations that HDACi can restore plasticity in adult visual cortex indicate that some epigenetic events are reversible and flexible even after the critical period.

\section{Conclusions}

Nearly a half century has elapsed since the original findings of a critical period for synaptic plasticity in the visual cortex [26]. While our understanding of the mechanisms underlying synaptic plasticity continues to grow at a staggering pace through elegant technological and innovative advances [47-49], a cure for amblyopia has yet to be discovered. We suggest that an increased understanding of the role of neuromodulators, homeostasis, and epigenetic modifications offer particular promise for future attempts at curing amblyopia and other cortically-based visual disorders. Moreover, we must appreciate the remarkable capacity for plasticity that the adult visual cortex maintains, at least in some species, and unlock the mechanisms underlying this competency. Given the fast pace of discovery within the field of visual cortex plasticity, the next half century may well bring a cure for amblyopia and, perhaps, other synaptopathies that can be modeled in the visual cortex [50].

\section{Acknowledgements}

Our work is supported by the National Eye Institute, the National Science Foundation, and the Simons Foundation. Portia McCoy is funded through NICHD training grant T32-HD40127. Hsien-Sung Huang is supported by a NARSAD Young Investigator Award. We thank Antoine Almonte, Serena Dudek, Rylan Larsen, Nicola Origlia, and Nate Sawtell for helpful comments on the review.

\section{References}

1. Frenkel MY, Bear MF. How monocular deprivation shifts ocular dominance in visual cortex of young mice. Neuron 2004;44:917-923. [PubMed: 15603735] 
2. Heynen AJ, Yoon BJ, Liu CH, Chung HJ, Huganir RL, Bear MF. Molecular mechanism for loss of visual cortical responsiveness following brief monocular deprivation. Nat Neurosci 2003;6:854-862. [PubMed: 12886226]

3. Turrigiano GG, Leslie KR, Desai NS, Rutherford LC, Nelson SB. Activity-dependent scaling of quantal amplitude in neocortical neurons. Nature 1998;391:892-896.896 [PubMed: 9495341] The first demonstration of synaptic scaling in visual cortical neurons. This study demonstrated that mEPSC amplitude increases following action potential blockade with TTX, suggesting that synaptic strengths increase to compensate for reduced neural activity. Conversely, synaptic strengths decrease following prolonged periods of hyperactivity induced by treatment with the GABAergic antagonist bicuculline.

4. Bienenstock EL, Cooper LN, Munro PW. Theory for the development of neuron selectivity: orientation specificity and binocular interaction in visual cortex. J Neurosci 1982;2:32-48. [PubMed: 7054394]

5. Bear MF, Singer W. Modulation of visual cortical plasticity by acetylcholine and noradrenaline. Nature 1986;320:172-176. [PubMed: 3005879]

6. Pettigrew JD, Kasamatsu T. Local perfusion of noradrenaline maintains visual cortical plasticity. Nature 1978;271:761-763. [PubMed: 625346]

7. Choi SY, Chang J, Jiang B, Seol GH, Min SS, Han JS, Shin HS, Gallagher M, Kirkwood A. Multiple receptors coupled to phospholipase $\mathrm{C}$ gate long-term depression in visual cortex. J Neurosci 2005;25:11433-11443. [PubMed: 16339037]

8. McCoy PA, McMahon LL. Muscarinic receptor dependent long-term depression in rat visual cortex is PKC independent but requires ERK1/2 activation and protein synthesis. J Neurophysiol 2007;98:1862-1870. [PubMed: 17634336]

9. Origlia N, Kuczewski N, Aztiria E, Gautam D, Wess J, Domenici L. Muscarinic acetylcholine receptor knockout mice show distinct synaptic plasticity impairments in the visual cortex. J Physiol 2006;577:829-840. [PubMed: 17023506]

10. Seol GH, Ziburkus J, Huang S, Song L, Kim IT, Takamiya K, Huganir RL, Lee HK, Kirkwood A. Neuromodulators control the polarity of spike-timing-dependent synaptic plasticity. Neuron 2007;55:919-929.929 [PubMed: 17880895] The authors show the critical involvement of neuromodulators in spike timing-dependent plasticity (STDP). The signaling pathways activated by receptor subtypes of the neuromodulators ACh and NE dictate the polarity of STDP induced, regardless of the relative timing of the pre- and post-synaptic action potentials used to induce the plasticity. Activation of adenylyl cyclase pathways trigger the induction of LTP and activation of phospholipase $\mathrm{C}$ pathways trigger the induction of LTD.

11. McCoy P, Norton TT, McMahon LL. Layer 2/3 synapses in monocular and binocular regions of tree shrew visual cortex express $\mathrm{mAChR}$-dependent long-term depression and long-term potentiation. $\mathrm{J}$ Neurophysiol 2008;100:336-345. [PubMed: 18480372]

12. Yamada K, Inagaki T, Funahashi R, Yoshimura Y, Komatsu Y. High-frequency stimulation together with adrenoceptor activation facilitates the maintenance of long-term potentiation at visual cortical inhibitory synapses. Cereb Cortex 2006;16:1239-1248. [PubMed: 16251503]

13. Abraham WC. Metaplasticity: tuning synapses and networks for plasticity. Nat Rev Neurosci 2008;9:387. [PubMed: 18401345]

14. Desai NS, Cudmore RH, Nelson SB, Turrigiano GG. Critical periods for experience-dependent synaptic scaling in visual cortex. Nat Neurosci 2002;5:783-789. [PubMed: 12080341]

15. Goel A, Lee HK. Persistence of experience-induced homeostatic synaptic plasticity through adulthood in superficial layers of mouse visual cortex. J Neurosci 2007;27:6692-6700. [PubMed: 17581956]

16. Jiang B, Trevino M, Kirkwood A. Sequential development of long-term potentiation and depression in different layers of the mouse visual cortex. J Neurosci 2007;27:9648-9652. [PubMed: 17804625]

17. Kaneko M, Stellwagen D, Malenka RC, Stryker MP. Tumor necrosis factor-alpha mediates one component of competitive, experience-dependent plasticity in developing visual cortex. Neuron 2008;58:673-680.680 [PubMed: 18549780]To test the possible involvement of synaptic scaling in the physiological consequence of monocular deprivation, the authors took advantage of the critical requirement for cytokine $\mathrm{TNF} \alpha$ for the expression of synaptic scaling. After the genetic or pharmacological block of $\mathrm{TNF} \alpha$, mice continued to exhibit a loss of the deprived eye response following monocular deprivation. However, mice failed to exhibit the subsequent enhancement of the open eye response, suggesting that synaptic scaling is involved in this phase of the ocular dominance shift. 
18. Kirkwood A, Rioult MC, Bear MF. Experience-dependent modification of synaptic plasticity in visual cortex. Nature 1996;381:526-528. [PubMed: 8632826]

19. Quinlan EM, Olstein DH, Bear MF. Bidirectional, experience-dependent regulation of N-methyl-Daspartate receptor subunit composition in the rat visual cortex during postnatal development. Proc Natl Acad Sci U S A 1999;96:12876-12880. [PubMed: 10536016]

20. Philpot BD, Cho KK, Bear MF. Obligatory role of NR2A for metaplasticity in visual cortex. Neuron 2007;53:495-502. [PubMed: 17296552]

21. Fagiolini M, Katagiri H, Miyamoto H, Mori H, Grant SG, Mishina M, Hensch TK. Separable features of visual cortical plasticity revealed by N-methyl-D-aspartate receptor 2A signaling. Proc Natl Acad Sci U S A 2003;100:2854-2859. [PubMed: 12591944]

22. Cho KK, Khibnik L, Philpot BD, Bear MF. The ratio of NR2A/B NMDA receptor subunits determines the qualities of ocular dominance plasticity in visual cortex. Proc Natl Acad Sci U S A 2009;106:5377-5382. [PubMed: 19276107]

23. Corlew R, Wang Y, Ghermazien H, Erisir A, Philpot BD. Developmental switch in the contribution of presynaptic and postsynaptic NMDA receptors to long-term depression. J Neurosci 2007;27:98359845. [PubMed: 17855598]

24. Crozier RA, Wang Y, Liu CH, Bear MF. Deprivation-induced synaptic depression by distinct mechanisms in different layers of mouse visual cortex. Proc Natl Acad Sci U S A 2007;104:13831388. [PubMed: 17227847]

25. Maffei A, Turrigiano GG. Multiple modes of network homeostasis in visual cortical layer $2 / 3$. J Neurosci 2008;28:4377-4384. [PubMed: 18434516]

26. Hubel DH, Wiesel TN. The period of susceptibility to the physiological effects of unilateral eye closure in kittens. J Physiol 1970;206:419-436. [PubMed: 5498493]

27. Hofer SB, Mrsic-Flogel TD, Bonhoeffer T, Hubener M. Prior experience enhances plasticity in adult visual cortex. Nat Neurosci 2006;9:127-132. [PubMed: 16327785]

28. Sawtell NB, Frenkel MY, Philpot BD, Nakazawa K, Tonegawa S, Bear MF. NMDA receptordependent ocular dominance plasticity in adult visual cortex. Neuron 2003;38:977-985.985 [PubMed: 12818182] This study employed chronic recordings of visual evoked potentials to demonstrate a remarkable capacity for adult plasticity. However, this plasticity differed from that observed in juveniles in that there was a lack of depression from the deprived eye, and the ocular dominance plasticity was instead produced by an enhancement of the open eye response. This shift required NMDA receptor-mediated plasticity, as ocular dominance plasticity was minimal in cortically-restricted NR1 knockout mice.

29. Fagiolini M, Hensch TK. Inhibitory threshold for critical-period activation in primary visual cortex. Nature 2000;404:183-186. [PubMed: 10724170]

30. Maya Vetencourt JF, Sale A, Viegi A, Baroncelli L, De Pasquale R, O'Leary OF, Castren E, Maffei L. The antidepressant fluoxetine restores plasticity in the adult visual cortex. Science 2008;320:385388. [PubMed: 18420937]

31. Pizzorusso T, Medini P, Berardi N, Chierzi S, Fawcett JW, Maffei L. Reactivation of ocular dominance plasticity in the adult visual cortex. Science 2002;298:1248-1251. [PubMed: 12424383]

32. McGee AW, Yang Y, Fischer QS, Daw NW, Strittmatter SM. Experience-driven plasticity of visual cortex limited by myelin and Nogo receptor. Science 2005;309:2222-2226. [PubMed: 16195464]

33. Gu Q, Liu Y, Cynader MS. Nerve growth factor-induced ocular dominance plasticity in adult cat visual cortex. Proc Natl Acad Sci U S A 1994;91:8408-8412. [PubMed: 8078895]

34. Sale A, Maya Vetencourt JF, Medini P, Cenni MC, Baroncelli L, De Pasquale R, Maffei L. Environmental enrichment in adulthood promotes amblyopia recovery through a reduction of intracortical inhibition. Nat Neurosci 2007;10:679-681. [PubMed: 17468749]

35. He HY, Ray B, Dennis K, Quinlan EM. Experience-dependent recovery of vision following chronic deprivation amblyopia. Nat Neurosci 2007;10:1134-1136.1136 [PubMed: 17694050]An elegant study demonstrating that amblyopia in the mature animal can be overcome through modifications in sensory experience. Amblyopia could be reversed by eliminating visual experience from both eyes prior to restoring normal vision to the previously deprived eye.

36. He HY, Hodos W, Quinlan EM. Visual deprivation reactivates rapid ocular dominance plasticity in adult visual cortex. J Neurosci 2006;26:2951-2955. [PubMed: 16540572] 
37. Hofer SB, Mrsic-Flogel TD, Bonhoeffer T, Hubener M. Experience leaves a lasting structural trace in cortical circuits. Nature. 2008 Here the authors suggest a possible mechanistic substrate to explain their prior observation that an initial monocular deprivation enables a more rapid ocular dominance shift upon a subsequent monocular deprivation in adults [33]. Using two photon imaging, the authors show that the initial deprivation causes a persistent increase in dendritic spine density that may facilitate future experience-dependent modifications.

38. Thompson B, Mansouri B, Koski L, Hess RF. Brain plasticity in the adult: modulation of function in amblyopia with rTMS. Curr Biol 2008;18:1067-1071. [PubMed: 18635353]

39. Majdan M, Shatz CJ. Effects of visual experience on activity-dependent gene regulation in cortex. Nat Neurosci 2006;9:650-659. [PubMed: 16582906]

40. Tropea D, Kreiman G, Lyckman A, Mukherjee S, Yu H, Horng S, Sur M. Gene expression changes and molecular pathways mediating activity-dependent plasticity in visual cortex. Nat Neurosci 2006;9:660-668. [PubMed: 16633343]

41. Barrett RM, Wood MA. Beyond transcription factors: the role of chromatin modifying enzymes in regulating transcription required for memory. Learn Mem 2008;15:460-467. [PubMed: 18583646]

42. Miller CA, Campbell SL, Sweatt JD. DNA methylation and histone acetylation work in concert to regulate memory formation and synaptic plasticity. Neurobiol Learn Mem 2008;89:599-603. [PubMed: 17881251]

43. Crosio C, Cermakian N, Allis CD, Sassone-Corsi P. Light induces chromatin modification in cells of the mammalian circadian clock. Nat Neurosci 2000;3:1241-1247. [PubMed: 11100144]

44. Naruse Y, Oh-hashi K, Iijima N, Naruse M, Yoshioka H, Tanaka M. Circadian and light-induced transcription of clock gene Per1 depends on histone acetylation and deacetylation. Mol Cell Biol 2004;24:6278-6287. [PubMed: 15226430]

45. Putignano E, Lonetti G, Cancedda L, Ratto G, Costa M, Maffei L, Pizzorusso T. Developmental downregulation of histone posttranslational modifications regulates visual cortical plasticity. Neuron 2007;53:747-759.759 [PubMed: 17329213]The authors show that experience-driven histone modifications are most prominent during early visual cortex maturation, and may be linked to specific signaling pathways. Importantly, ocular dominance plasticity can be reactivated in adults by treatments with a histone deacetylase inhibitor (trichostatin A). This is one of the first demonstrations that epigenetic modifications may be crucial for gating critical period plasticity.

46. Di Cristo G, Berardi N, Cancedda L, Pizzorusso T, Putignano E, Ratto GM, Maffei L. Requirement of ERK activation for visual cortical plasticity. Science 2001;292:2337-2340. [PubMed: 11423664]

47. Sugiyama S, Di Nardo AA, Aizawa S, Matsuo I, Volovitch M, Prochiantz A, Hensch TK. Experiencedependent transfer of Otx2 homeoprotein into the visual cortex activates postnatal plasticity. Cell 2008;134:508-520. [PubMed: 18692473]

48. Mank M, Santos AF, Direnberger S, Mrsic-Flogel TD, Hofer SB, Stein V, Hendel T, Reiff DF, Levelt $\mathrm{C}$, Borst A, et al. A genetically encoded calcium indicator for chronic in vivo two-photon imaging. Nat Methods 2008;5:805-811. [PubMed: 19160515]

49. Mrsic-Flogel TD, Hofer SB, Ohki K, Reid RC, Bonhoeffer T, Hubener M. Homeostatic regulation of eye-specific responses in visual cortex during ocular dominance plasticity. Neuron 2007;54:961972. [PubMed: 17582335]

50. Dolen G, Osterweil E, Rao BS, Smith GB, Auerbach BD, Chattarji S, Bear MF. Correction of fragile X syndrome in mice. Neuron 2007;56:955-962. [PubMed: 18093519] 
Presynaptic
bouton

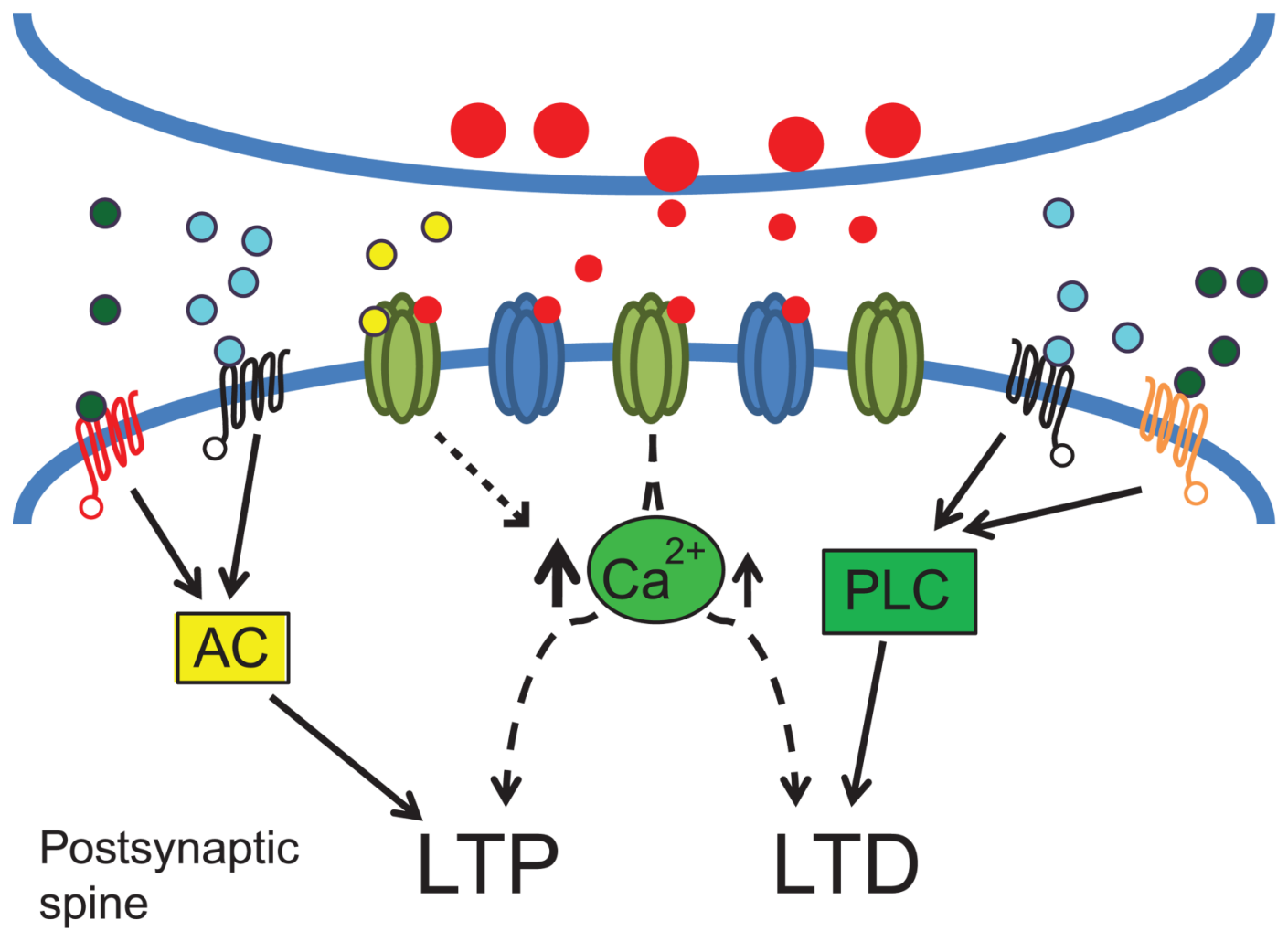

$\mathrm{ACh}$

O Histamine

epinephrine

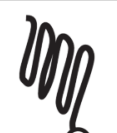

mAChR
aAR

$\beta A R$
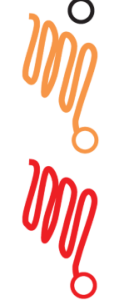

BAR

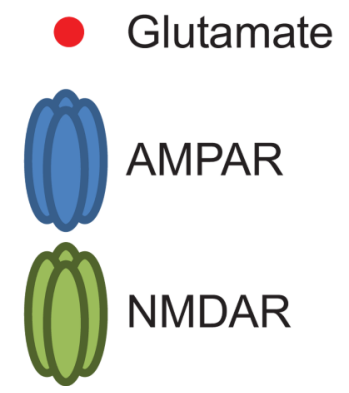

Figure 1. Neuromodulators direct the valence of synaptic plasticity through distinct signaling pathways

mAChR or $\alpha_{1} A R$ stimulation induces LTD through a PLC-dependant cascade, whereas mAChR or $\beta A R$ activation of AC induces LTP. Enhancement of NMDAR currents by histamine augments LTP, possibly through increasing intracellular calcium levels. These observations suggest that activation of specific signaling pathways through discrete neuromodulator receptor subtypes dictates the direction of plasticity induced in visual cortex. AC: Adenylyl cyclase; ACh: Acetylcholine; $\alpha_{1}$ AR: alpha adrenergic receptor; $\beta$ AR: beta adrenergic receptor; LTD: Long-term depression; LTP: Long-term potentiation; mAChR: 
Muscarinic acetylcholine receptor; NMDAR: N-methyl d-aspartate receptor; PLC: Phospholipase C. 


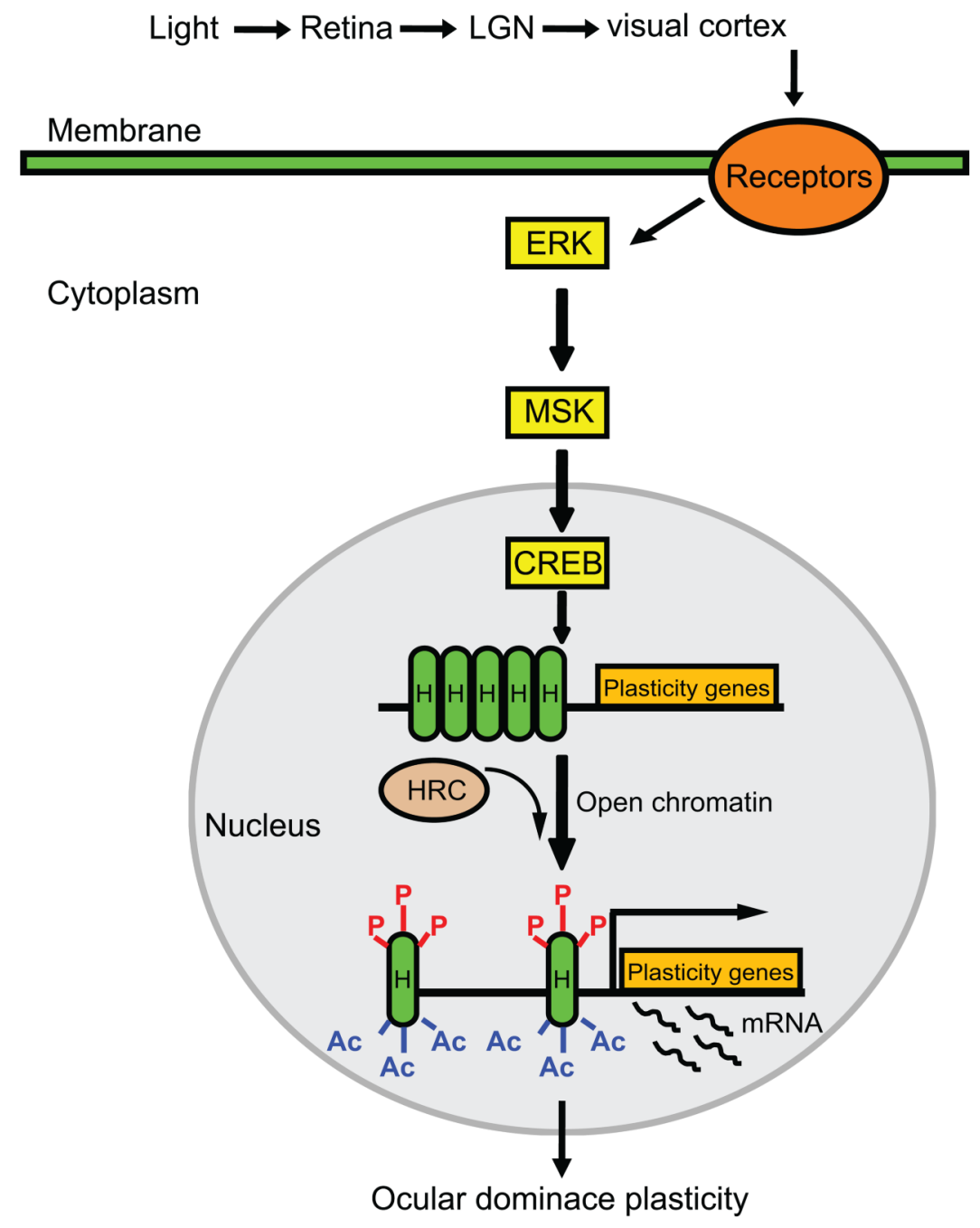

H

Histone octamer

2. $\mathrm{mRNA}$

ERK

Extracellular signal-regulated kinase

Ac Acetyl group

P Phospho group

CREB

cAMP- response element binding protein

Figure 2. Epigenetic remodeling of chromatin can enable ocular dominance plasticity through an ERK-mediated cascade

Visual experience (light) can activate ERK and its downstream neural targets, MSK and CREB. CREB-mediated transcription is normally modest, due to a tight chromatin conformation. A histone remodeling complex can open the chromatin conformation through phosphorylation and acetylation of histone $\mathrm{H} 3$, thereby increasing the rate of CREB-mediated transcription of plasticity genes. Activation of plasticity gene expression contributes to the ocular dominance plasticity in the visual cortex. LGN: lateral geniculate nucleus; MAPK: mitogen-activated protein kinase; ERK: extracellular signal-regulated kinase; MSK: mitogen-and stress-activated 
kinase; CREB: cAMP-response element binding protein; HRC: histone remodeling complex; P: phospho group; Ac: acetyl group; H: histone octamer. 